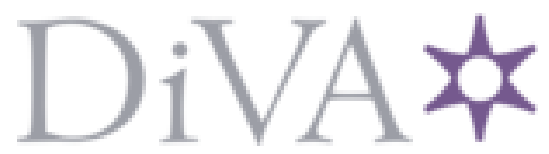

http://www.diva-portal.org

This is the published version of a paper published in Holzforschung.

Citation for the original published paper (version of record):

Bonarski, J., Kifetew, G., Olek, W. (2015)

Effects of cell wall ultrastructure on the transverseshrinkage anisotropy of Scots pine wood.

Holzforschung, 69(4): 501-507

http://dx.doi.org/10.1515/hf-2014-0075

Access to the published version may require subscription.

N.B. When citing this work, cite the original published paper.

Permanent link to this version:

http://urn.kb.se/resolve?urn=urn:nbn:se:Inu:diva-40868 
Jan T. Bonarski, Girma Kifetew and Wiesław Olek*

\section{Effects of cell wall ultrastructure on the transverse shrinkage anisotropy of Scots pine wood}

\begin{abstract}
A hypothesis for explaining the differential anisotropic shrinkage behavior of wood has been proposed, and it was based on the differences in the cell wall ultrastructure. The starting point of the consideration is that wood shrinkage is governed by its chemical composition, ultrastructure, and gross anatomy. It is also well known that the transverse shrinkage anisotropy of earlywood (EW) is more pronounced than that of the latewood (LW). In the paper, the cell wall ultrastructure and shrinkage anisotropy has been related to each other, and to this purpose, a set of crystallographic texture descriptors was applied. The descriptors are based on X-ray diffraction (XRD) experiments conducted on matched EW samples from different growth rings of Scots pine. The range of the microfibril angle (MFA) was identified. The ratio of the maxima of inverse pole figures (IPFs) of both the tangential (T) and radial (R) directions was determined. The ratios quantify the inhomogeneity of the spatial arrangement of the ordered areas. The results of the study clearly indicate that the transverse shrinkage of wood is governed mostly by a specific ultrastructural organization of moderately organized cell wall compounds.
\end{abstract}

Keywords: cellulose, crystallographic texture analysis, dimensional instability, hemicelluloses, inverse pole figures (IPFs), microfibril angle (MFA), polymer distribution in cell walls, Scots pine wood (Pinus sylvestris L.)

DOI 10.1515/hf-2014-0075

Received March 11, 2014; accepted September 22, 2014; previously published online $\mathrm{xx}$

*Corresponding author: Wiestaw Olek, Faculty of Wood Technology, Poznań University of Life Sciences, ul. Wojska Polskiego 28, 60-637 Poznań, Poland, e-mail: olek@up.poznan.pl Jan T. Bonarski: Institute of Metallurgy and Materials Science, Polish Academy of Sciences, ul. Reymonta 25, 30-059 Kraków, Poland Girma Kifetew: Faculty of Engineering, Linnæus University, Lückligs plats 1, 351-95 Växjö, Sweden
Introduction

Wood is a cellular anisotropic biocomposite, the cell walls of which consist of heteropolymers with a supramolecular architecture. Wood properties can be interpreted at various levels of organization. The transverse shrinkage anisotropy of wood is well characterized at the gross level (macrolevel). However, the details in this context are not at all clear. To gain more insight into this matter, an interpretation at the ultrastructural level (microlevel and nanolevel) offers more opportunities.

At the polymer level, the cell walls consist of cellulose, hemicelluloses, and lignin, which are accompanied by minor amounts of extractives and mineral substances. The cell wall is an interconnected network or, in other words, a 3D biopolymer composite (Rowell et al. 2005). These polymers have different hygroscopic properties due to their chemical composition as well as ultrastructural organization. In general, wood shrinkage is governed by the chemical composition, ultrastructure (supramolecular architecture), and gross anatomy. In normal wood, the longitudinal (L) shrinkage from the green to the ovendried condition is equal to approximately $0.1 \%-0.3 \%$, and it can be considered as negligible for practical purposes. The transverse shrinkage has distinctly higher values, and it reveals a significant anisotropy, that is, tangential (T) shrinkage is usually 1.5-2.5 times that of the radial (R) shrinkage (Spear and Walker 2006).

There is a large body of literature concerning the studies of the mechanisms governing the differential shrinkage behavior of wood, and several theories were proposed, which can be subdivided into five groups (Pentoney 1953; Kelsey 1963; Skaar 1988) focusing on (1) the effects of the gross structure such as ray cell alignment, (2) the interaction between earlywood (EW) and latewood (LW), (3) the differences in the mean microfibril angle (MFA) values in the T and R cell walls, (4) the cell wall layering (the middle lamella theory), and (5) the geometrical distribution of cell wall tissues.

It is partly believed that rays play the most important role in restraining $\mathrm{R}$ shrinkage, as the ray tissue shrinks less in the $\mathrm{R}$ direction. In the case of the broad-rayed wood species, such as oak and beech, shrinkage results may 
support the hypothesis that rays are one of the factors responsible for transverse shrinkage anisotropy, because the ray volume is up to $17 \%-22 \%$ of the wood tissue in oak and beech (Skaar 1988). However, Boutelje (1962) denied the importance of rays with this regard in softwood species.

In the EW-LW interaction theory, called the Mörath theory (Pentoney 1953), the difference in R and $\mathrm{T}$ shrinkage is primarily attributed to the differences in the density of EW and LW. Accordingly, the bands of LW force the bands of EW to shrink tangentially by almost as much as of LW. In the R direction, both the EW and LW shrink independently, that is, they act in series and the total $\mathrm{R}$ shrinkage is the weighted mean shrinkage of the LW and EW (Spear and Walker 2006). Pentoney (1953) and Boutelje (1962) tried to evaluate the influence of the Mörath theory on the differential shrinkage. Kifetew et al. (1997) suggested a relationship for calculating the gross $\mathrm{T}$ and $\mathrm{R}$ shrinkage of Scots pine based on the isolated EW and LW interaction.

The crystalline and paracrystalline celluloses of wood cell walls have limited capacity to absorb water molecules as well as to change its length or cross-section. On the contrary, the amorphous matrix formed by lignin and hemicelluloses easily binds or releases water and manifests distinct tendency to swell or shrink. The matrix shrinkage is especially restrained in the direction parallel to the microfibril axis. Therefore, cell walls tend to shrink excessively in the plane transverse to the microfibrils. On the $\mathrm{R}$ walls, the mean MFA of the S2 layer of softwood is often greater than that of the T walls (Skaar 1988). Pentoney (1953) calculated the transverse shrinkage ratio in the most extreme case with MFA of the T wall of $0^{\circ}$ and $45^{\circ}$ for the $\mathrm{R}$ wall. It was concluded that the difference in MFA between the R and T walls may contribute to the differential shrinkage, but it is not a decisive factor of the shrinkage anisotropy. However, $\mathrm{Gu}$ et al. (2001) reported that the MFA of S2 on the crosssection of cell wall has a considerable contribution to the shrinkage anisotropy of Scots pine.

The middle lamella theory is based on observations that the $\mathrm{R}$ middle lamella is thicker than the $\mathrm{T}$ middle lamella (Frey-Wyssling 1940), and this observation was considered as the major cause of the transverse shrinkage anisotropy. However, experimental results do not support the significance of this theory.

Boutelje (1973) argued that the major factor governing the transverse anisotropic behavior of pine and spruce is the geometrical distribution of the cell wall in the tissue. Kifetew (1999) conducted both theoretical calculations based on a finite element model and experiments and found no evidence that supports this theory.

The gross properties of wood are significantly influenced by the ultrastructural composition (supramolecular architecture) of the polymers in the cell wall. In this context, the MFA is the most often applied parameter in correlating properties to the ultrastructure. Such correlations were also found for wood hygroexpansion (Meylen 1968; Skaar 1988). Another parameter considered in this regard was the crystallite size of the crystalline cellulose (Washusen and Evans 2001). The hygroexpansion property of wood strongly depends on its sorption behavior. Therefore, the concept of crystallinity was often applied for quantifying fractions of accessible and nonaccessible cellulose in moisture sorption (Rowell et al. 2005).

The spatial organization of wood at the ultrastructural level was already recognized as nonuniform, and it revealed preferred spatial orientation of the ordered areas, which makes the structure strongly anisotropic and complex. Therefore, the application of a single parameter (i.e., the mean MFA or crystallinity) would be insufficient for describing the complexity of wood ultrastructure in the 3D space. Olek and Bonarski (2006) as well as Bonarski and Olek (2006) implemented the 3D texture analysis for materials with the monoclinic crystal symmetry ascribed to the lattice cell of cellulose (Zugenmaier 2008). The analysis allowed us to obtain the orientation distribution function (ODF) being a probability of the density of orientations of ordered areas related to the sample anatomical coordinate system.

Another feature of the texture analysis is its application for the determination of the inverse pole figures (IPFs). An IPF is an angular distribution of a chosen sample direction with respect to the crystal coordinate system (Engler and Randle 2010). Therefore, the IPFs are directly related to the main anatomical directions of wood (i.e., the L, R, and $T$ ones). The IPFs may be used to identify the spatial organization of wood compounds having different crystallographic organization (i.e., cellulose and hemicelluloses) and relate their contribution to the anatomical directions. Thus, it might explain the anisotropy of some wood properties at the ultrastructural level. The combination of such analysis with sorption and hygroexpansion properties of wood components would have special importance for explaining the shrinkage anisotropy of wood.

The objective of the study was to verify the hypothesis on the differences in cell wall compound organization as a mechanism governing the transverse anisotropic shrinkage behavior of wood.

\section{Materials and methods}

Two types of experiments have been conducted: shrinkage measurements and crystallographic texture determination. Both experiments 
were performed on matched Scots pine EW (Pinus sylvestris L.) samples. The material was obtained from a 60 -year-old tree harvested in Sweden. Clear EW samples were obtained for three positions in the cross-section: (a) juvenile heartwood from the $9^{\text {th }}$ growth ring, (b) mature heartwood from the $18^{\text {th }}$ growth ring, and (c) mature sapwood from the $42^{\text {nd }}$ growth ring.

The shrinkage measurements were conducted on clear and saturated EW samples. The samples in a shape of rectangular prisms were cut, and their thickness was consistent with the R direction and equal to approximately $2.8,1.7$, and $1.8 \mathrm{~mm}$, respectively, for the three positions in the cross-section (i.e., for the $9^{\text {th }}, 18^{\text {th }}$, and $42^{\text {nd }}$ growth rings). The remaining two dimensions of the samples were equal to 15 and $20 \mathrm{~mm}$ and consistent with the $\mathrm{T}$ and $\mathrm{L}$ directions, respectively. The samples were firstly soaked in distilled water to ensure their maximum swelling. The $\mathrm{R}$ and $\mathrm{T}$ dimensions of the swelled samples were measured with a digital caliper, with an accuracy of $0.01 \mathrm{~mm}$. The measurements were made at three different and fixed positions in each anatomical direction and the averaged values were further considered in calculations. Then, the samples were oven dried for about $12 \mathrm{~h}$ and the measurements of the $\mathrm{R}$ and $\mathrm{T}$ dimensions were repeated for each sample. Finally, the transverse shrinkage ratio $\left(\alpha_{\mathrm{T}} / \alpha_{\mathrm{R}}\right)$ was determined for each position in the cross-section.

The X-ray diffraction (XRD) experiments were performed with the Philips X'Pert system, which was equipped with a texture goniometer ATC-3, for the positioning control of the examined samples. The experimentally determined XRD patterns were used to select reflections for which the experimental pole figures were determined. The filtered $\mathrm{X}$-ray radiation $\mathrm{CoK} a(l=0.179026 \mathrm{~nm})$ was applied. The samples in a shape of rectangular prisms were prepared for the XRD experiments. The dimensions of the samples were $2.5 \times 15 \times 20 \mathrm{~mm}$ for the $\mathrm{R}, \mathrm{T}$, and $\mathrm{L}$ directions, respectively. The TL plane of EW was subjected to the XRD experiments and the volume of the investigated material was equal to approximately $0.8 \mathrm{~mm}^{3}$. The large volume of the material allowed us to obtain the averaged characteristics of the ultrastructure. During a single XRD experiment, 642 individual diffraction patterns were registered. It allowed us to increase the reliability and representativeness of the results (Bonarski and Olek 2011; Olek and Bonarski 2012). The Schulz back-reflection technique (Schulz 1949) was applied to register a set of the incomplete pole figures of the (101), (001), and (010) planes. Due to a partial coincidence, the diffraction signals for singular reflections were extracted by a mathematical modeling of the registered spectra. The 3D ODFs were determined from the experimental pole figures for all sets of the investigated samples. The ODFs were obtained according to the modified procedure, which was implemented for the materials characterized by the monoclinic lattice symmetry (Bonarski and Olek 2006; Olek and Bonarski 2006). The application of the ODF made it possible to account for the texture-independent diffraction (Bonarski et al. 2000) and background halo intensities of the crystalline and amorphous phases, respectively. Thus, the less ordered wood compounds (i.e., paracrystalline cellulose, hemicelluloses, and lignin) could be considered as contributing to the diffraction signal (Åkerholm and Salmén 2003; Stevanic and Salmén 2009).

\section{Results and discussion}

The mean transverse shrinkage ratio of the $\mathrm{T}$ to $\mathrm{R}$ directions $\left(\alpha_{\mathrm{T}} / \alpha_{\mathrm{R}}\right)$ was calculated for each position in the transverse cross-section based on the shrinkage data from the green to oven-dried state (Table 1).

The texture experiments were informative in terms of the spatial distribution of the crystallographic orientations within the cell wall. The crystallographic texture was described by ODFs, which were used for deriving numerous crystallographic descriptors useful for the

Table 1 Transverse shrinkage ratio and crystallographic descriptors at different positions in the cross-section of Scots pine heartwood and sapwood.

\begin{tabular}{|c|c|c|c|c|c|c|}
\hline Wood position in the cross-section & $\alpha_{\mathrm{T}} / \alpha_{\mathrm{R}}$ & $\mathrm{IPF}(\mathrm{T})_{\max } / \mathrm{IPF}(\mathrm{R})_{\max }$ & $\Delta \boldsymbol{\mu}_{\mathrm{T}} / \Delta \boldsymbol{\mu}_{\mathrm{R}}$ & $I_{\mathrm{T}}$ & $I_{\mathrm{R}}$ & $I_{\mathrm{T}} / I_{\mathrm{R}}$ \\
\hline Juvenile heartwood $9^{\text {th }}$ growth ring & $2.55 \pm 0.13$ & 0.45 & 1.36 & 37.55 & 23.63 & 1.59 \\
\hline Mature heartwood $18^{\text {th }}$ growth ring & $2.42 \pm 0.22$ & 0.53 & 1.20 & 30.35 & 26.70 & 1.13 \\
\hline Mature sapwood $42^{\text {nd }}$ growth ring & $2.17 \pm 0.05$ & 0.66 & 1.25 & 40.63 & 30.36 & 1.34 \\
\hline
\end{tabular}
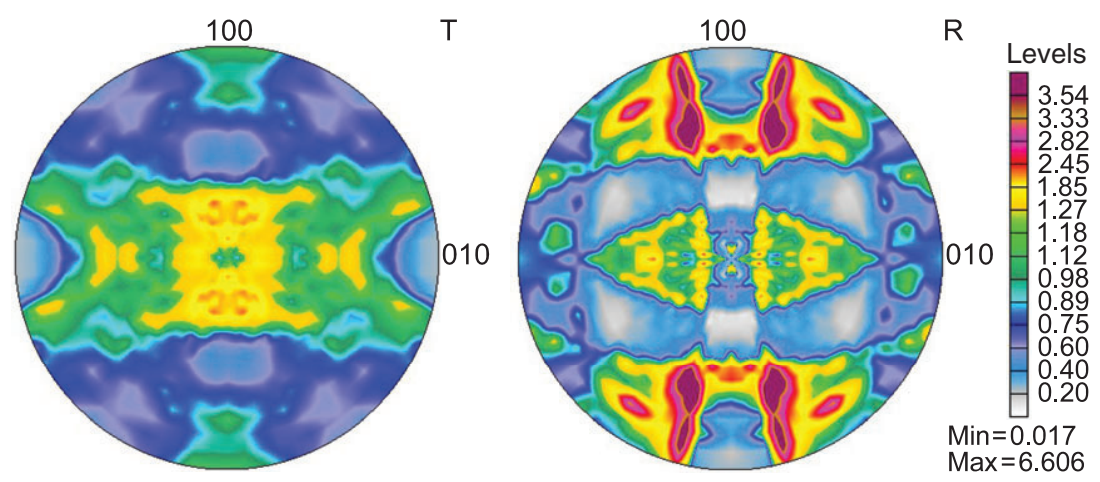

Figure 1 IPFs of T and R anatomical directions for heartwood (juvenile wood from the $9^{\text {th }}$ growth ring). 

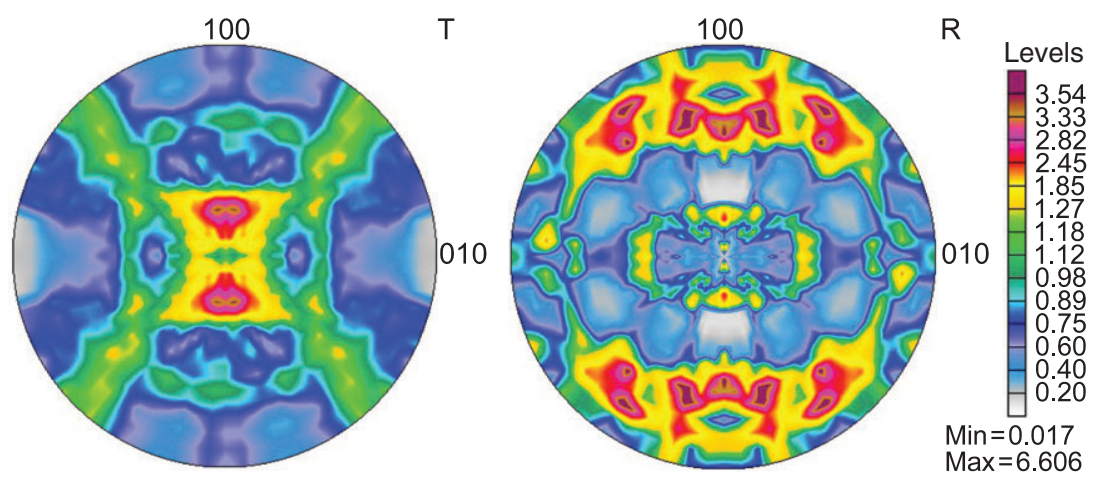

Figure 2 IPFs of T and R anatomical directions for heartwood (mature wood from the $18^{\text {th }}$ growth ring).
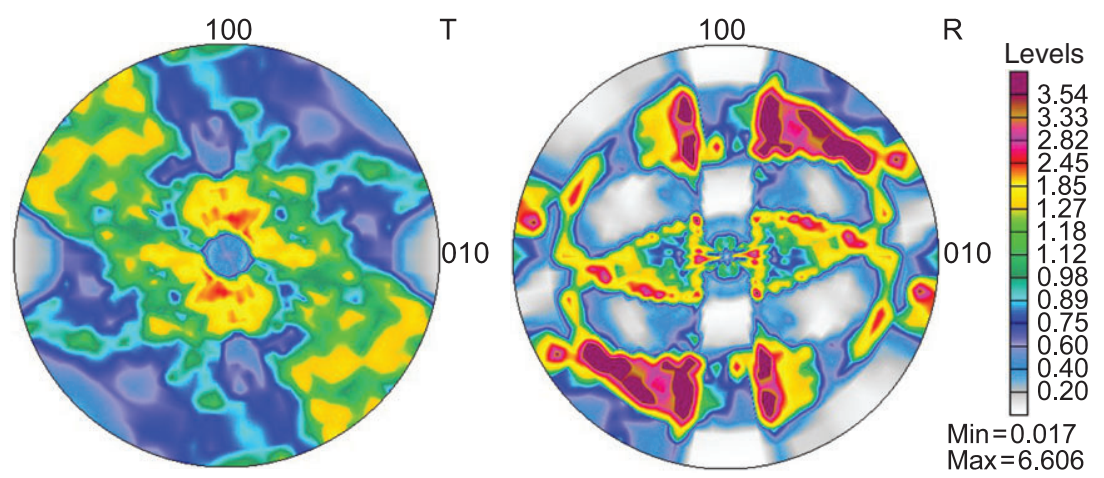

Figure 3 IPFs of T and R anatomical directions for sapwood (mature wood from the $42^{\text {nd }}$ growth ring).

evaluation of anisotropy of wood ultrastructure. The IPFs were directly related to the spatial organization of the wood compounds and were important descriptors of the ultrastructure. The IPFs of the $\mathrm{T}$ and $\mathrm{R}$ directions are presented in Figures 1-3.

The maximum values of IPFs were calculated for the $\mathrm{T}$ direction (i.e., $\mathrm{R}$ cell wall), IPF(T) ${ }_{\max }$, and for the $\mathrm{R}$ direction (i.e., $\mathrm{T}$ cell wall), $\operatorname{IPF}(\mathrm{R})_{\max }$. Then, the ratio of the maxima was calculated as $\operatorname{IPF}(\mathrm{T})_{\max } / \mathrm{IPF}(\mathrm{R})_{\max }$. The ratio quantified the differences in the spatial arrangement of the ordered areas along both anatomical directions. The values of the ratio as obtained for the investigated three positions in the cross-section are given in Table 1. The significant differences in the orientation distribution of the polymers were found for the $\mathrm{T}$ and $\mathrm{R}$ anatomical directions when analyzing the IPFs (Figures 1-3). The IPFs revealed
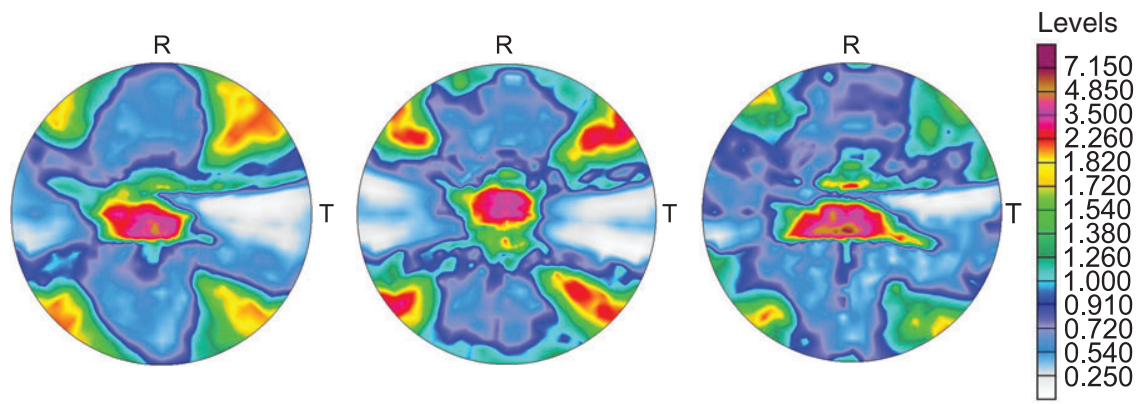

Min $=0.118$

$\operatorname{Max}=7.019$

Figure 4 Complete pole figures of the (010) lattice plane as obtained from the rotated ODF: heartwood juvenile wood $9^{\text {th }}$ growth ring (left), heartwood mature wood $18^{\text {th }}$ growth ring (center), and sapwood mature wood $42^{\text {nd }}$ growth ring (right). 
the crystallographic planes of the ordered as well as less ordered areas, which were located perpendicularly to the individual anatomical directions. Regarding the natural anisotropy of cellulose crystallites and less organized hemicelluloses, the IPFs directly indicated the global anisotropy of ultrastructure within the cell wall. It was primary because the differences were identified for the $T$ and $R$ directions. The differences in this regard were lower for the organized components of the cell wall under consideration of the shrinkage. The IPF(T) $)_{\max }$ data were lower than those of the $\operatorname{IPF}(R)_{\text {max }}$ and it can be explained as a higher tendency for shrinking in the $\mathrm{T}$ direction. The relation was observed for all investigated positions in the cross-section (Table 1). However, the ratio $\operatorname{IPF}(\mathrm{T})_{\max } / \mathrm{IPF}(\mathrm{R})_{\max }$ was increasing with the growth rings and it was interpreted that the impact of less organized components was decreasing. The ratios of $\mathrm{IPF}(\mathrm{T})_{\max } / \mathrm{IPF}(\mathrm{R})_{\max }$ can be directly correlated with the calculated values of the shrinkage ratio $\left(\alpha_{\mathrm{T}} / \alpha_{\mathrm{R}}\right)$ for all investigated growth rings (Table 1).

The pole of the (010) lattice plane of the crystalline cellulose represents, by definition, the "b" lattice period of the unit cell being approximately coaxial with the longitudinal direction of microfibrils. Thus, the spatial arrangement of the (010) poles depicts the distribution of values of the MFA (i.e., the most common descriptor of wood ultrastructure). However, due to physical reasons (i.e., the relatively low diffraction intensity of the 040 reflection available for measurements), the direct identification of the singular (010) pole distribution [i.e., the (010) pole figure] is relatively difficult and erroneous from a point of view of the texture interpretation. The ODF is calculated from a set of complementary pole figures [e.g., (101), (001), and (010) registered on 101, 002, and 040 reflections by XRD]. The calculated ODF allows, by definition, to determine the spatial distribution of any (hkl) lattice plane (i.e., to recalculate pole figures, including the nonmeasurable ones). Moreover, the calculated ODF allows to obtain the IPFs related to any virtual cross-section of the examined material. The sophisticated property of the ODF also allows to project the spatial distribution of the (010) plane onto the RT plane of wood. Thus, such selected reference system of the (010) pole figure reveals directly the spatial distribution of the MFA. The above-described feature of the ODF, as derived from the experimental pole figures registered on the TL plane of the investigated wood, served for determining the MFA distribution. It was made by the $90^{\circ}$ rotation of the ODF around the T direction (Figure 4).

The traditional methods for characterizing wood ultrastructure are usually limited for determining the angle between the axes of cellulose microfibrils and the longitudinal direction of cells (i.e., MFA) (Barnett and
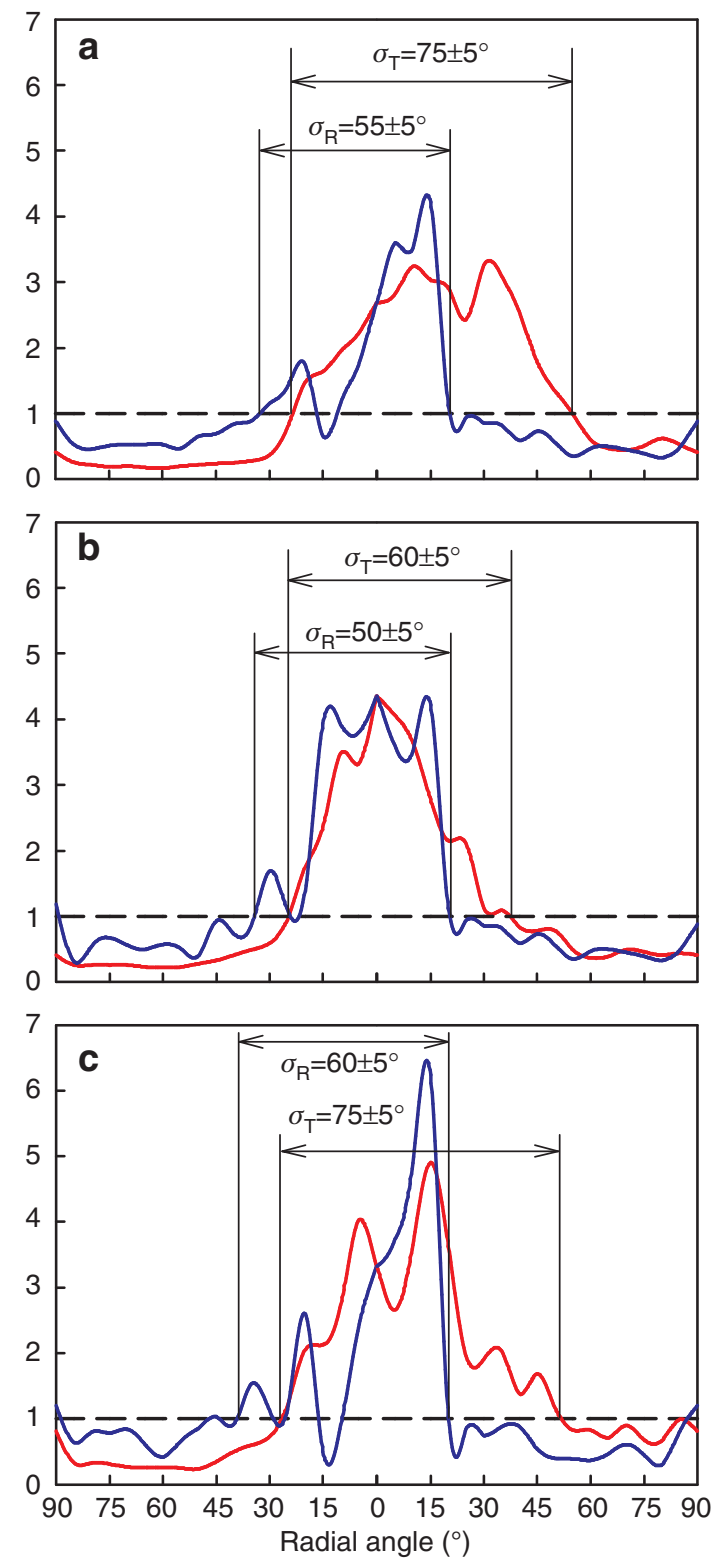

Figure 5 Intensity profiles of the (010) pole figures revealed by the RL plane (blue curve) and TL plane (red curve) together with the MFA variation for the T and R directions $\left(\sigma_{T}\right.$ and $\sigma_{R}$ ): (a) heartwood juvenile wood $9^{\text {th }}$ growth ring, (b) heartwood mature wood $18^{\text {th }}$ growth ring, and (c) sapwood mature wood $42^{\text {nd }}$ growth ring.

Note: Level 1 was selected to distinguish between the organized and random areas of cell wall compounds (Bunge 1982).

Bonham 2004). Both the microscopic techniques and XRD give rise only to mean values of MFA, although the MFA values differ to some extent within the cell walls. The approach applied in the present study made it possible to find the differences in the MFA values related to individual anatomical directions. Thus, the angular ranges of the MFA as related to the $\mathrm{T}$ and $\mathrm{R}$ directions were determined 
and denoted as $\Delta u_{\mathrm{T}}$ and $\Delta u_{\mathrm{R}}$, respectively (Bonarski and Olek 2007). The ranges were directly measured from the central zone of the complete pole figures given in Figure 4 and applied to quantify the MFA variation. The ultrastructure anisotropy was quantified by the $\Delta \mu_{\mathrm{T}} / \Delta \mu_{\mathrm{R}}$ ratio and presented in Table 1 . The values of the angular range were also revealed by the intensity profiles of the (010) pole figures projected on the RL and TL planes (Figure 5). The scheme of tracing intensity profiles (Figure 6) was marked on the pole-grid projection for the RL (left) and TL (right) planes, respectively. The MFA variation in intensity profiles was denoted as $\sigma_{\mathrm{T}}$ and $\sigma_{\mathrm{R}}$ for the T and R directions, respectively. Also, these descriptors clearly accounted for the ultrastructural anisotropy as shown in Figure 5.

The intensity profiles depict that the MFA values are varying in some angular range around the $\mathrm{L}$ axis. Moreover, the variation is asymmetrical with respect to the $\mathrm{L}$ axis. The presented profiles also show that the range and character of the MFA values in the T direction is essentially higher than in the $\mathrm{R}$ direction (Figure 5). The left and right side limits of the MFA variation were determined by the intersection of the intensity profiles, with the intensity value of 1 being considered as the limit of random crystallographic orientation (Figure 5). The integrated intensities of the profiles $\left(I_{\mathrm{T}}\right.$ and $\left.I_{\mathrm{R}}\right)$ as well as their ratio $\left(I_{\mathrm{T}} / I_{\mathrm{R}}\right)$ were also determined. These descriptors indicate the differences in the microfibril arrangement in the selected anatomical directions (Table 1).

Although the crystallographic descriptors derived from the strongest XRD signal account for the shrinkage anisotropy, they are not as accurate as the $\operatorname{IPF}(\mathrm{T})_{\max } / \mathrm{IPF}(\mathrm{R})_{\max }$ ratios. It is especially obvious when relating the crystallographic descriptors and the shrinkage ratio $\left(\alpha_{\mathrm{T}} / \alpha_{\mathrm{R}}\right)$ for the subsequent positions in the cross-section. The ratios of the angular range of the MFA $\left(\Delta u_{\mathrm{T}} / \Delta u_{\mathrm{R}}\right)$ and integrated intensities of the profiles of the (010) pole figures account for the arrangement of cellulose microfibrils. Therefore, the application of these crystallographic descriptors is characterized by similar drawbacks, as the theory accounts for the differences in the MFA values in the R and T cell walls. However, the crystallographic descriptors applied in the present study delivered more information on the ultrastructure compared to the traditional concept of MFA. The method reported in the paper avoids erroneous measurements of MFA due to the direct registration of poor diffraction intensity of the 040 reflection. The MFA measurements based on the 040 reflection seem to be possible to some extent in the sophisticated synchrotron experiments with a very narrow X-ray beam (Lichtenegger et al. 1999). The other advantage of the reported method is a lack of the internal discrepancy of the experimental pole figures registered for relatively homogeneous surface layers on the examined LT anatomical plane, which is impossible in a case of another planes (especially the RT one). Moreover, the presented method can be easily applied in any laboratory having conventional XRD instrument equipped with a texture goniometer.

\section{Conclusions}

The significant differences in cell wall polymer distribution were found by means of IPFs of the $\mathrm{T}$ and $\mathrm{R}$ anatomical directions. The differences can be quantified by the IPF maxima ratio $\operatorname{IPF}(\mathrm{T})_{\max } / \mathrm{IPF}(\mathrm{R})_{\max }$, which clearly show
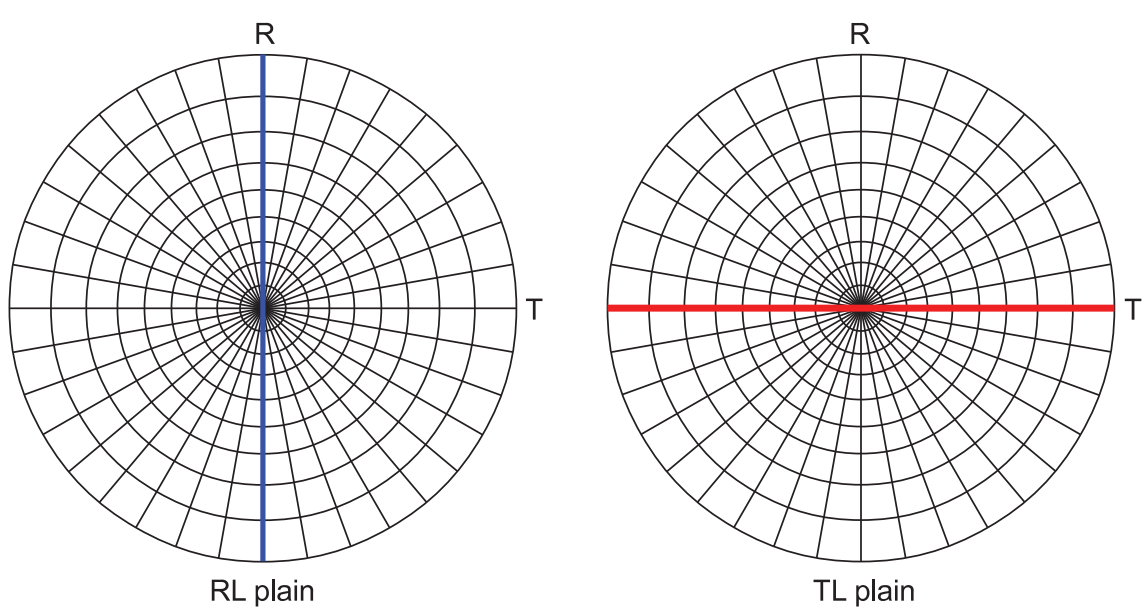

Figure 6 Pole grid applied in the visualization of the (010) pole figure with trace of the RL (left) and TL (right) planes. 
lower maximum values in the $\mathrm{T}$ direction compared to the $\mathrm{R}$ direction. This finding was interpreted as that the lower fraction of highly organized components of wood cell wall was found in the $\mathrm{T}$ direction, and consequently, in this direction, the higher content of hemicelluloses (i.e., less organized phase) was recognized. The lower IPF(T) max $_{\text {max }}$ can be interpreted as a more pronounced tendency for shrinking in $\mathrm{T}$ than in $\mathrm{R}$ direction. It can be safely concluded that a relation between shrinkage ratio $\alpha_{\mathrm{T}} / \alpha_{\mathrm{R}}$ and the ratio $\operatorname{IPF}(\mathrm{T})_{\max } / \mathrm{IPF}(\mathrm{R})_{\text {max }}$ is established. Accordingly, the observation seems to support the hypothesis on the influence of the differences in the preferred spatial distribution of hemicelluloses as a mechanism governing the transverse anisotropic shrinkage behavior of Scots pine wood.

The applied crystallographic descriptors gave a similar tendency, as it was earlier observed for the IPF analysis. However, the relation between the descriptors and the shrinkage ratio was not so clear for all studied positions in the cross-section. It again may support the hypothesis that the differences in microfibril alignment in the $\mathrm{R}$ and $\mathrm{T}$ walls contribute to the anisotropic shrinkage behavior. However, they might not be a governing factor in explaining the shrinking anisotropy.

A general relation was found that the strongly preferred crystallographic orientation is developed in a given anatomical direction where less shrinkage is observable.

Acknowledgments: The work was financially supported by the National Science Centre as the 2011/01/M/NZ9/00028 research grant.

\section{References}

Åkerholm, M., Salmén, L. (2003) The oriented structure of lignin and its viscoelastic properties studied by static and dynamic FT IR spectroscopy. Holzforschung 57:459-465.

Barnett, J.R., Bonham, V.A. (2004) Cellulose microfibril angle in the cell wall of wood fibres. Biol. Rev. 79:461-472.

Bonarski, J., Olek,W. (2006) Texture function application for wood ultrastructure description. Part 1. Theory. Wood Sci. Technol. 40:159-171.

Bonarski, J.T., Olek, W. (2007) Preferred crystallographic orientation in mature and juvenile wood. Z. Kristallogr. 222:199-203.

Bonarski, J.T., Olek, W. (2011) Application of the crystalline volume fraction for characterizing the ultrastructural organization of wood. Cellulose 18:223-235.

Bonarski, J.T., Wróbel, M., Pawlik, K. (2000) Quantitative phase analysis of duplex stainless steel using incomplete pole figures. Mater. Sci. Technol. 16:657-662.
Boutelje, J. (1962) The relationship of structure to transverse anisotropy in wood with reference to shrinkage and elasticity. Holzforschung 16:33-46.

Boutelje, J. (1973) On the relationship between structure and the shrinkage and swelling of wood in Swedish pine and spruce. Sven. Papperstidn. 76:78-83.

Bunge, H.J. Texture Analysis in Materials Science. Butterworths, London, 1982.

Engler, O., Randle, V. Introduction to Texture Analysis: Macrotexture, Microtexture, and Orientation Mapping. 2nd ed. CRC Press, Boca Raton, 2010.

Frey-Wyssling, A. (1940) Die Ursache der anisotropen Schwindung des Holzes. Holz Roh Werkst. 3:349-353.

Gu, H., Zink-Sharp, A., Sell, J. (2001) Hypothesis on the role of cell wall structure in differential transverse shrinkage of wood. Holz Roh Werkst. 59:436-442.

Kelsey, K.E. (1963) A critical review of the relationship between the shrinkage and structure of wood. CSIRO Division of Forest Products, Melbourne, Technological Paper No. 28, 35 pp.

Kifetew, G. (1999) The influence of the geometrical distribution of cell-wall tissues on the transverse anisotropic dimensional changes of softwood. Holzforschung 53:347-349.

Kifetew, G., Lindberg, H., Wiklund, M. (1997) Tangential and radial deformation field measurements on wood during drying. Wood Sci. Technol. 31:35-44.

Lichtenegger, H., Müller, M., Paris, O., Riekel, Ch., Fratzl, P. (1999) Imaging of the helical arrangement of cellulose fibrils in wood by synchrotron X-ray microdiffraction. J. Appl. Crystallogr. 32:1127-1133.

Meylen, B.A. (1968) Cause of high longitudinal shrinkage in wood. For. Prod. J. 18:75-78.

Olek, W., Bonarski, J. (2006) Texture function application for wood ultrastructure description. Part 2. Application. Wood Sci. Technol. 40:336-349.

Olek, W., Bonarski, J.T. (2012) Influence of cyclic sorption on wood ultrastructure. BioResources 7:1729-1739.

Pentoney, R.E. (1953) Mechanisms affecting tangential vs. radial shrinkage. J. For. Prod. Res. Soc. 3:27-32.

Rowell, R.M., Pettersen, R., Han, J.S., Rowell, J.S., Tshabalala, M.A. (2005) Cell wall chemistry. In: Handbook of Wood Chemistry and Wood Composites. Eds. Rowell, R.M., CRC Press, Boca Raton.

Schulz, L.G. (1949) A direct method of determining preferred orientation of a flat reflection sample using a Geiger counter X-ray spectrometer. J. Appl. Phys. 20:1030-1033.

Skaar, C. Wood-Water Relations. Springer, Berlin, 1988.

Spear, M., Walker, J. Dimensional instability in timber. In: Primary Wood Processing. Principles and Practice. Ed. Walker, J., 2nd ed. Springer, Berlin, 2006.

Stevanic, J.S., Salmén, L. (2009) Orientation of the wood polymers in the cell wall of spruce wood fibres. Holzforschung 63:497-503.

Washusen, R., Evans, R. (2001) Prediction of wood tangential shrinkage from cellulose crystallite width and density in one 11-yearold tree of Eucalyptus globulus Labill. Aust. For. 64:123-126.

Zugenmaier, P. Crystalline Cellulose and Derivatives: Characterization and Structures. Springer, Berlin, 2008. 